УДК 330

DOI 10.17308/econ.2020.1/2747

\title{
ГЕНЕЗИС И РАЗВИТИЕ ПОНЯТИЯ «ИНФРАСТРУКТУРА» В РАБОТАХ ЗАРУБЕЖНЫХ И ОТЕЧЕСТВЕННЫХ ИССЛЕДОВАТЕЛЕЙ
}

\begin{abstract}
М. Н. Бахтин, А. Ю. Кособуцкая
Воронежский государственный университет

И. А. Дядюн

Институт сервиса, туризма и дизайна Северо-Кавказского федерального университета

Поступила в редакцию 12 декабря 2019 г.

Аннотация: исследуют происхождение и гносеология понятия «инфраструктура», выделяются особенности и основные подходы зарубежных и отечественных исследователей к определению данного понятия, представлена авторская трактовка.

Ключевые слова: инфраструктура, зарубежные и отечественные подходы к определению, требования к понятию, особенности.

Abstract: the article examines the origin and epistemology of the term «infrastructure», highlights the features and main approaches of foreign and domestic researchers to the definition of this term, presents the author's interpretation.
\end{abstract}

Key words: infrastructure, foreign and domestic approaches to definition, requirements for the concept, features.

Изучение научной литературы позволило сформировать обширную базу теоретических исследований инфраструктуры как экономической категории и позволило сделать вывод, что в настоящее время в экономической литературе отсутствует единое общепринятое определение понятия «инфраструктура».

По информации, представленной в международном этимологическом словаре, термин «инфраструктура» (лат. infra - под, ниже и structure строение, расположение) впервые встречается в 1875 г. во французской научной литературе и начиная с 1887 г. используется в англоязычных источниках. При этом отмечается, что под инфраструктурой понимается совокупность сооружений, формирующих основу любой операции или системы, первоначально в военном смысле [1].

Тем не менее теоретические основы исследования влияния инфраструктуры на воспроизводственный процесс были заложены гораздо раньше. Так, еще в XVIII в. представители классической

(С) Бахтин М. Н., Кособуцкая А. Ю., Дядюн И. А., 2020 политической экономии А. Смит и Д. Рикардо осознавали, что рост производства невозможен без создания новых цехов и складских помещений, строительства общежитий для рабочих, прокладки коммуникаций и дорог... А. Смит видел роль инфраструктуры (хотя и не использовал этот термин) в обеспечении нужд производства и отмечал, что данные объекты неинтересны для частного капитала в силу их неспособности приносить немедленную прибыль. В «Исследовании о природе и причине богатства народов» (Кн. 5) Смит говорит о такой обязанности государства, как «основание и содержание общественных учреждений и общественных работ, которые, будучи в самой высокой степени полезными для обширного общества в целом, не могут, однако, своей прибылью возместить расходы отдельного человека или небольшой группы людей». В ряду таких благ он упоминает и транспорт, утверждая, что «хорошие дороги, водные пути и гавани содействуют торговле любой страны» и что «если шоссе, мосты, каналы и т. п. ...сооружаются и поддерживаются торговлей, которая ведется при посредстве их, то они могут быть 
сооружены только там, где торговля требует их и, следовательно, есть в них надобность» [2].

К. Маркс и Ф. Энгельс в развитии общественных отношений отводили инфраструктуре вспомогательную роль. К. Маркс определял объекты инфраструктуры как внешние материальные условия обеспечения производства, «...в более широком смысле к средствам процесса труда относятся все материальные условия, необходимые вообще для того, чтобы процесс мог совершаться. Прямо они не входят в него, но без них он или совсем невозможен, или может происходить лишь в несовершенном виде» [3, с. 191]. Маркс использовал такие соответствующие инфраструктуре по своему социально-экономическому содержанию категории, как «общие условия труда» [4, с. 182], «всеобщие условия производства» [5, с. 22], «общие условия производства», «материальные условия, необходимые для того, чтобы процесс труда мог совершаться» и «общие условия капиталистического производства» [6, с. 191, 400, 525]. Очевидно, что одни из этих условий являются природными (или естественными), а другие создаются человеком в процессе его трудовой деятельности (что правомерно рассматривать как производственную инфраструктуру).

А. Маршалл в труде «Принципы политической науки» (Кн. 6, гл. 12) отмечал, что бо̀льшая часть прибыли, полученная в ходе промышленного развития XIX в. Великобританией, была обусловлена «снижением издержек перевозки людей и товаров... поскольку главным экономическим событием века является развитие не обрабатывающих, а транспортных отраслей» [7].

Дж. М. Кларк выделил накладные издержки (overhead expense) на микроуровне (связанные с содержанием снабженческих и сбытовых фирм, финансово-аудиторских контор, фирм, занимающихся изучением спроса, рекламной деятельностью, научно-техническим и информационным обслуживанием и т. д.) и макроуровне (связанные с развитием отраслей, необходимых для функционирования рынка в целом и способствующих развитию частного капитала в сфере производства и обращения, такие как транспорт и связь, складское хозяйство и другие отрасли, обеспечивающие товарное обращение) [8].

Термин «инфраструктура» стал активно использоваться западными экономистами с конца 40-х гг. ХХ в.

Существует мнение (позиция П. Самуэльсона), что в 1953 г. понятие «инфраструктура» ввел в эко- номическую науку П. Розенштейн-Родан, который использовал его по отношению ко «всем условиям окружающей общественной среды, необходимым для того, чтобы частная промышленность была в состоянии сделать первый рывок для развития» [9, с. 60]. П. Розенштейн-Родан определял инфраструктуру «как комплекс общих условий, обеспечивающих благоприятное развитие частного предпринимательства в основных отраслях экономики и удовлетворяющих потребности всего населения» [там же]. Он полагал, что инфраструктура включает в себя такие базовые отрасли экономики, как транспорт, связь, энергетика, и предназначена для обслуживания частной промышленности. При этом исследователя в значительной степени интересовали развивающиеся страны и дающие возможность развития частного предпринимательства инвестиции в инфраструктурные объекты (теория «большого толчка»). По мнению Е. Е. Савченко, «в дальнейшем на этой основе определилась конкретная область исследования инфраструктуры западными экономистами, выражающаяся в общих условиях развития общественного производства, имеющих цель создания благоприятных условий для развития частного капитала» $[10$, с. 59].

В соответствии с другой точкой зрения (позиция А. Янгсона) пальма первенства принадлежит Х. Зингеру, который в начале 40-х гг. ХХ в. выделял капитал прямопроизводительный и капитал накладной, или накладные издержки общества (overhead capital), которые представляют собой инвестиции в инфраструктуру. В 1964 г. Х. Зингер в рамках теории «большого толчка» предложил концепцию «сбалансированного роста посредством несбалансированных инвестиций», согласно которой повышение производительности труда может быть достигнуто за счет развития собственной производственной и социальной инфраструктуры, что даст толчок развитию всей экономики и позволит создать самоподдерживающий рост [11]. Данный факт, по мнению Е. А. и В. А. Благининых, «свидетельствует не только о схожести трактовок Х. Зингера и П. Розенштейна-Родана, но и о своевременном понимании влияния и важности инфраструктурного развития» [12, с. 980].

В 1950-1960-е гг. исследования инфраструктуры ведутся преимущественно во взаимосвязи с такими понятиями, как «накладные расходы» и «производственные издержки» (Р. Нурксе [13], П. Розенштейн-Родан, У. Ростоу [14] и др.), параллельно происходит переосмысление данного понятия в рамках институциональной парадигмы (Р. Йохим- 
сен [15]). В конце 1960-х - начале 1970-х гг. акцент смещается с изучения вопросов воздействия инфраструктуры на экономический рост на анализ инфраструктуры как фактора развития экономики, а государственные средства рассматриваются как основной источник инвестиций в инфраструктуру, а инфраструктурные блага и услуги являются объектом государственного обеспечения и контроля (работы П. Самуэльсона, А. Янгсона, Ж. Штолера, А. Пезенти, М. Портера, П. Рассела и др.). При этом в состав инфраструктуры включали и непроизводственную сферу.

Так, П. Самуэльсон определял инфраструктуру как «крупные капиталовложения, предпринимаемые исключительно государством и закладывающие предпосылки для успешного развития частного сектора: они расчищают путь для производства и торговли» [16]. Исключительную роль государства в данном инвестиционном процессе он объяснял тем, что «масштабы некоторых из них слишком велики для ограниченных рынков частного капитала, а другие будут окупаться в течение слишком длительного срока, чтобы частные инвесторы очень ими интересовались» [там же, с. 324]. При этом инфраструктура «способствует созданию определенного равновесия во времени и пространстве» [там же]. А. Янгсон разделяет указанную позицию и считает, что по своей природе инвестиции в инфраструктуру неприбыльны, и поэтому они выступают как накладные издержки общества (overhead costs) [17, c. 31]. А. Пизенти отмечал, что инфраструктура (дорожная сеть, транспортные средства, землеустройство и т. п.) «сокращают накладные расходы капиталистических предприятий, т. е. улучшают экономическую среду, в которой те действуют, облегчая процесс обращения капитала...» $[18$, с. 115$]$.

По мнению Р. Йохимсена, объекты инфраструктуры (которые он подразделял на материальные, институциональные и персональные) служат «повышению степени интеграции и уровня экономической деятельности» $[15$, с. 100]. Р. Нурксе писал, что инфраструктура выполняет «функции своего рода "кровеносной системы" народнохозяйственного организма» и «призвана бесперебойно, рационально и четко обслуживать весь процесс "обмена веществ" в народном хозяйстве» [13, с. 45-97]. У. Ростоу рассматривал инфраструктуру в качестве инструмента эффективного удовлетворения потребностей растущего населения [14].

В этот же период инфраструктура приобретает характерные черты как экономическая категория. Так, в 1965 г. Ж. Штолер выделил следующие чер- ты инфраструктуры: технические (неделимость сооружений, долгий срок жизни), институциональные (дефицитность инфраструктурных объектов, централизованные контроль и руководство, отсутствие рыночных цен), экономические (бездействие принципа исключения, отсутствие потребительского суверенитета, готовность общества взять на себя финансирование, большой внешний эффект, высокий риск инвестиций, недостаточность индивидуального предвидения) [19].

К 1980-м гг. инфраструктура, по мнению Н. С. Малафеева, стала рассматриваться преимущественно как часть концепции общественного капитала [20, с. 1140]. Исследование Д. Ашауэра [21, с. 177-200] фактически дало толчок целой концепции экономического развития на основе инфраструктуры, в рамках которой проводятся эконометрические исследования производительности инфраструктуры и ее влияния на результативность частного сектора экономики.

В результате анализа трудов зарубежных экономистов Е. Е. Савченко определяет два подхода к раскрытию сущности инфраструктуры: функциональный и структурный [10, с. 61].

Н. С. Малафеев считает, что длительный период развития понятия «инфраструктура» предопределил два ведущих подхода к его определению: атрибутивный, характеризующий инфраструктуру «по трем атрибутам: технологическому (капитальный товар или благо...), экономическому (источник внешней экономии, общественное или социально значимое благо и источник внешних эффектов) и институциональному (инфраструктурные блага и услуги - объект государственного обеспечения и государственного контроля)», и функциональный, предполагающий, что вклад каждого экономического агента в создание общественного продукта определяется его обеспеченностью инфраструктурой $[20$, с. 1140$]$.

П. А. Пыхов и Т. О. Кашина выделяют такие зарубежные подходы к исследованию инфраструктуры, как концепция накладных расходов (П. Самуэльсон, Д. Кларк), институциональная концепция (Р. Иохимсон и др.), концепция экономического роста (У. Ростоу, У. Артур Льюис, Р. Нурксе и др.), маркетинговая концепция (Ф. Котлер) [22, с. 40].

Мы считаем, что указанные подходы не противоречат друг другу, а позволяют дать разностороннее представление о трактовках понятия «инфраструктура» в зарубежной литературе.

Что касается отечественной экономической мысли, то истоки исследований инфраструктуры 
относят к работам Д. И. Менделеева и А. И. Чупрова. При этом необходимо отметить, что на ранних стадиях исследования инфраструктуры ученые концентрировали свое внимание по преимуществу на отдельных ее составляющих. Например, А. И. Чупров [23] занимался изучением инфраструктурной проблематики на примере железнодорожного транспорта.

Первые исследования инфраструктуры советскими экономистами опирались на теоретические постулаты К. Маркса, а в центре их внимания находился инфраструктурный комплекс социалистической экономики. По мнению В. А. Благинина $[12$, с. 980$]$, самое раннее упоминание термина «инфраструктура» в советской науке принадлежит профессору С. А. Хейнману, который под инфраструктурой понимал «комплекс отраслей, обслуживающих материальное производство» [24, с. 74] и сводил ее задачи к производственным.

Популярным предметом исследования инфраструктура становится в 1960-е гг., после проведения ряда научных конференций, посвященных роли инфраструктуры в капиталистическом воспроизводстве и вопросам инфраструктуры развивающихся стран.

В советский период считалось, что к признакам инфраструктуры главным образом относится потребность экономического субъекта в ее существовании, а ее выделение обеспечивает возможность «...более точно судить о таких ее элементах, которые обеспечивают общие условия для развития экономических и социальных процессов с точки зрения создания объективных материальных возможностей для эффективного функционирования овеществленного и живого труда» [25, с. 35].

Ю. А. Жаравина выделила пять основных этапов изучения инфраструктуры отечественными учеными, при этом каждому этапу характерен фокус на определенные ключевые проблемы исследования [26, с. 61]. В силу того что первые два этапа относятся к советскому периоду, понятие «инфраструктура» определялось с точки зрения централизованной системы хозяйствования и отражало особенности ее функционирования. В переходный период в исследованиях активно разрабатывались понятие «рыночная инфраструктура» и вопросы развития инфраструктурного обеспечения в экономической политике государства. На современном этапе происходит выявление уровней формирования инфраструктуры в экономических системах.

Как отмечает Е. Б. Хоменко, «отечественные ученые по ряду позиций продолжили традиции советской школы в исследованиях инфраструктуры экономики, в некоторых аспектах расширили и дополнили зарубежные концепции рыночной инфраструктуры, обогатив их новыми трактовками понятийного аппарата и классификациями состава инфраструктуры» [27, с. 15].

По настоящее время отсутствует общепринятое понятие инфраструктуры, однако при изучении инфраструктуры как экономической категории, по мнению Р. Б. Палякина и Н. В. Каленской, традиционно используются функциональный, воспроизводственный и институциональный подходы, при этом в качестве объекта исследования выступает инфраструктура во взаимосвязи с конкретной организационно-экономической системой, ее субъектным и объектным составом [28].

Е. Б. Дворядкина и Е. Э. Сапожникова [29, с. 46], Е. Е. Савченко $[10$, с. 62$]$ и авторы данной статьи [30] расширяют количество подходов к определению понятия «инфраструктура» до шести (воспроизводственный, отраслевой, функциональный, территориальный, системный и эволюционный подходы) и отмечают, что эволюция указанных подходов происходила в соответствии с развитием экономики в целом.

По определению многих исследователей, в настоящее время научные работы в области инфраструктуры посвящены изучению проблем развития социальной, производственной, экологической, рыночной, отраслевой, телекоммуникационной (информационной), инновационной и других видов инфраструктуры. При этом отдельные виды инфраструктур рассматриваются во взаимосвязи и взаимозависимости.

Таким образом, исходя из анализа теоретических источников, мы можем сформулировать такие требования к понятию «инфраструктура», как наличие материально-вещественного содержания, наличие стоимостной характеристики, совокупность внутренних функций, общих для всех объектов инфраструктуры, институциональное содержание [31]. Это общие требования, существенные для любой социально-экономической системы. В то же время инфраструктуру от иных систем отличают следующие особенности: функциональная вторичность (зависимость от обеспечиваемого объекта), многочисленность объектов, функционирование которых обусловлено наличием и состоянием инфраструктуры; способность концентрировать время и пространство (основные характеристики систем по Г. Клейнеру) и, исходя из этого, трансформировать обслуживаемые системы. 
В результате анализа научных источников делаем следующее обобщение: «инфраструктура»интегральная экономическая категория, составляющие которой могут относиться к разным отраслям экономики, но объединены общей целью - они создают условия для устойчивого функционирования и развития экономического производства, товарного обмена и жизнеобеспечения в стране или регионе и обеспечивают пространственную

\section{ЛИТЕРАТУРА}

1. Online Etymology Dictionary. - URL: www. etymonline.com

2. Смит А. Исследование о природе и причинах богатства народов / A. Смит. - URL: http://www.e-reading. club/book.php?book=100806

3. Маркс К. Сочинения / К. Маркс, Ф. Энгельс. - Изд. 2-е. - М. : Государственное издательство политической литературы, 1960. - Т. 2. Глава V : Процесс труда и процесс увеличения стоимости.

4. Маркс К. Сочинения / К. Маркс, Ф. Энгельс. - Изд. 2-е. - М. : Государственное издательство политической литературы, 1960. - Т. 24. - 657 с.

5. Маркс К. Сочинения / К. Маркс, Ф. Энгельс. - Изд. 2-е. - М. : Государственное издательство политической литературы, 1969. - Т. 46. Часть II : Экономические рукописи К. Маркса 1857-1859 годов.

6. Маркс К. Сочинения / К. Маркс, Ф. Энгельс. - Изд. 2-е. - М. : Государственное издательство политической литературы, 1960. - Т. 23. -920 с.

7. Маршалл А. Принципы политической науки/ А. Маршалл. - URL: http://www.eklit.org/marsod.html

8. Clark J. M. Studies in the Economics of Overhead Costs / J. M. Clark. - Chicago : University of Chicago Press, 1923.

9. Rosenstein-Rodan P. N. Notes on the Theory of the «Big Push» / P. N. Rosenstein-Rodan // Economic Development for Latin America: proceedings of a conference held by the International Economic Association / eds. H. S. Ellis and H. C. Wallich. - London : Macmillan, 1961.

10. Савченко E. E. Теоретико-методологические подходы к исследованию системообразующей инфраструктуры на этапе трансформации экономического пространства региона : дис... д-ра экон. наук : 08.00 .05 / Е. Е. Савченко. - Иркутск, 2016. - 363 с. - URL: http:// science.usue.ru/images/docs/downl/savchenko/savchenko. pdf

11. Singer $H . W$. International Development : Growth and Change / H. W. Singer. - N. Y., 1964.

12. Благинин E. А. Ретроспективный анализ научных взглядов на понятие «транспортная инфраструктура региона» / Е. А. Благинин, В. А. Благинин // Фундаментальные исследования. - 2016. - № 11. - С. 979-984.

13. Nurkse R. Problems of capital formation in underveloped countries / R. Nurkse. - Oxford : University Press, 1953. целостность территории, в первую очередь экономическую целостность.

Таким образом, инфраструктура - это всегда подсистема в рамках системы более высокого порядка [20, с. 16]. В то же время, так как инфраструктура имеет системный характер, то ее изучение должно происходить путем разложения на подсистемы второго порядка, которые в свою очередь должны быть поделены на элементы более низкого порядка.

14. Rostow W. W. The Stages of Economic Growth / W. W. Rostow. - London : Cambridge University Press, 1962.$324 \mathrm{p}$.

15. Jochimsen $R$. Theorie der Infrastruktur, Grundlagen der marktwirtschaftlichen Entwicklung / R. Jochimsen. Tubingen : JCBMohr (PaulSiebeck), 1966.

16. Самуэльсон П. Экономика : учебник : в 2 т. / П. Самуэльсон. - М. : Алгон, 1992. - Т. 2. - 740 с.

17. Youngson A. Overhead capital. Study development economics / A. Youngson. - Edinburgh : University Press, 1967.

18. Пизенти А. Очерки политической экономии капитализма / А. Пизенти. - М. : Прогресс, 1976. - Т. 2.

19. Муравьева М. В. Краткий аналитический обзор исследований инфраструктуры в агропромышленном комплексе / М. В. Муравьева // Современные проблемы науки и образования. - 2014. - № 4. - URL: http://www. science-education.ru/ru/article/view?id=14232

20. Малафеев Н. С. Концепция инфраструктуры в экономических исследованиях / Н. С. Малафеев // Российские регионы в фокусе перемен : сб. докладов XI Междунар. конф. : в 2 т. - Екатеринбург, 2016. - С. 1138-1146.

21. Aschauer D. A. Is Public Expenditure Productive? D. A. Aschauer // Journal of Monetary Economics. - 1989. Vol. 23, no. 2. - P. 177-200.

22. Пыхов П. А. Инфраструктура как объект экономических исследований / П. А. Пыхов, Т. О. Кашина // Журнал экономической теории. - 2016. - № 1. - С. 39-46.

23. Чупров А. И. Железнодорожное хозяйство. Его экономические особенности и его отношение к интересам страны / А. И. Чупров. - М. : Типография А. И. Мамонтова и Ко, 1875. - URL: https://vas-s-al.livejournal. com/717547.html

24. Хейнман С. А. Научно-техническая революция и структурные изменения в экономике СССР / С. А. Хейнман // Коммунист. - 1969. - № 14. - С. 74.

25. Тощенко Ж. T. Социальная инфраструктура : сущность и пути развития / Ж. Т. Тощенко. - М. : Мысль, 1980. $-206 \mathrm{c}$.

26. Жаравина Ю. А. Производственная инфраструктура как фактор повышения конкурентоспособности национального хозяйства : дис. ... канд. экон. наук. СПб., 2006. -225 с.

27. Хоменко Е. Б. Генезис и гносеология концептуальных положений теории инфраструктуры в экономических исследованиях / Е. Б. Хоменко // Социально- 
экономическое управление: теория и практика. - 2013. № 1 (23). - С. 13-17.

28. Палякин Р. Б. Развитие инфраструктуры предпринимательства : агентно-ориентированный подход / Р. Б. Палякин, Н. В. Каленская // Казанский экономический вестник. - 2016. - № 4 (24). - С. 36-39.

29. Дворядкина Е. Б. Кредитные организации как элемент региональной рыночной инфраструктуры / Е. Б. Дворядкина, Е. Э. Сапожникова // Вестник Челябинского государственного университета. - 2008. № 29. - C. 45-51.

Воронежский государственный университет Бахтин М. Н., аспирант кафедры экономики и управления организащиями

E-mail: bakhtinmn@yandex.ru

Кособуикая А. Ю., доктор экономических наук, дочент кафедры экономики и управления организаичиям

E-mail: anna.rodnina@mail.ru

Институт сервиса, туризма и дизайна Северо-Кавказского федерального университета, г. Пятигорск

Дядюн И. А., младший научный сотрудник отдела планирования и организачуии научно-исследовательской работь

E-mail: iwka275@yandex.ru
30. Бахтин М. Н. Транспортная инфраструктура региона : основные подходы к определению понятия / М. Н. Бахтин // Регион. - 2019. - № 3 (46). - С. 87-93.

31. Бахтин М. Н. Проблемы инфраструктурного обеспечения социально-экономического и пространственного развития регионов / М. Н. Бахтин // Управление изменениями в социально-экономических системах : сб. статей междунар. науч.-практ. конф. Вып. 17 / под ред. Ю. И. Трещевского, Г. В. Голиковой. - Воронеж : Истоки, 2018. - С. 13-27.

\section{Voronezh State University}

Bakhtin M. N., Postgraduate Student of the Department of Economics and Management of Organizations

E-mail:bakhtinmn@yandex.ru

Kosobutskaya A. Yu., Doctor of Economics, Associate Professor of the Department of Economics and Management of Organizations

E-mail: anna.rodnina@mail.ru

Institute of Service, Tourism and Design of the North Caucasian Federal University, Pyatigorsk branch

Dyadyun I. A., Junior Research Scientist of the Department of Planning and Organization of Academic Research Work

E-mail: iwka275@yandex.ru 